\title{
Malaria and acute kidney injury
}

\author{
Denver D. Brown ${ }^{1} \cdot$ Sonia Solomon ${ }^{1} \cdot$ Daniele Lerner $^{1} \cdot$ Marcela Del Rio $^{1}$
}

Received: 8 June 2018 / Revised: 19 December 2018 / Accepted: 28 December 2018 / Published online: 31 January 2019

(C) IPNA 2019

\begin{abstract}
Malaria is a parasitic infection transmitted by mosquitos, resulting in significant morbidity and mortality. It affects 212 million worldwide, causing death in up to 303,000 children annually. In the USA, up to 1700 people are affected yearly. Although the prevalence in developed countries is less than in developing countries, travelers from low transmission areas, and those from endemic areas who later return, are very susceptible to malaria and its complications. Severe malaria can cause significant multiorgan dysfunction including acute kidney injury (AKI). The pathogenesis is not clearly understood but proposed mechanisms include acute tubular necrosis (ATN) due to impediments in renal microcirculation, infection-triggered proinflammatory reactions within the kidney, and metabolic disturbances. Providers must consider malarial infection in cases of AKI in someone with a travel history, as early recognition and treatment are crucial to improving outcomes. This article will review malariainduced AKI in order to provide a better understanding of this infection's effect on the kidneys.
\end{abstract}

Keywords Malaria $\cdot$ Acute kidney injury $\cdot$ Blackwater fever $\cdot$ FEAST trial

\section{Background of malarial AKI}

Although endemic to certain regions, malaria carries significant morbidity and mortality worldwide. The United States (US), by virtue of travelers to these endemic areas, is not unaffected. In surveillance reports from 2014, the US had a confirmed 1724 cases of malaria, including one of congenital transmission [1]. Infants and children have been identified as being at particular risk for poor outcomes from the complications of severe malarial infection [2-5].

Acute kidney injury (AKI) is a relatively frequent complication of severe malaria. The reported incidence of malariainduced AKI in the pediatric population has been variable (depending on factors such as the definition of AKI and the cohort studied), with some estimates as high as 46\% [2, 6-9]. Adult literature, along with some pediatric studies, describe that when impaired renal function develops in the setting of malarial infection, it is associated with increased mortality [2, $5,8,10,11]$. Travelers from low transmission areas are very

Denver D. Brown

denvbrow@montefiore.org

1 Department of Pediatric Nephrology at The Children's Hospital at Montefiore, 3326 Bainbridge Ave, Bronx, NY 10029, USA susceptible to malaria and its complications because of their lack of immunity. Additionally, travelers who emigrate from endemic areas who then return later, having lost their immunity, are also at risk [11]. The disease may not cause symptoms until after return from high transmission areas. Due to the significant clinical morbidity associated with this disease, it is of integral importance that providers understand its multiorgan impact. This article will review malaria-induced AKI in order to provide a better understanding of this infection's effect on the renal organ system.

\section{Pathogenesis of malarial AKI}

While the pathogenesis of malarial AKI is not fully understood, there are a number of proposed mechanisms. Three prevailing hypotheses include hemodynamic (mechanical) perturbations, immune-mediated glomerular injury, and metabolic disturbances [12-14] (see Fig. 1).

The first hypothesis posits that the disease is primarily caused by hemodynamic derangement from parasitized red blood cells adhering to adjacent healthy erythrocytes, platelets, and the capillary endothelium (cytoadherence) [15]. This results in the formation of intravascular clusters and rosettes. The infected RBCs can sequester in the deep vascular beds of the kidney disrupting microcirculation as well as peripherally pool, leading to anemia, thrombocytopenia, impaired blood 


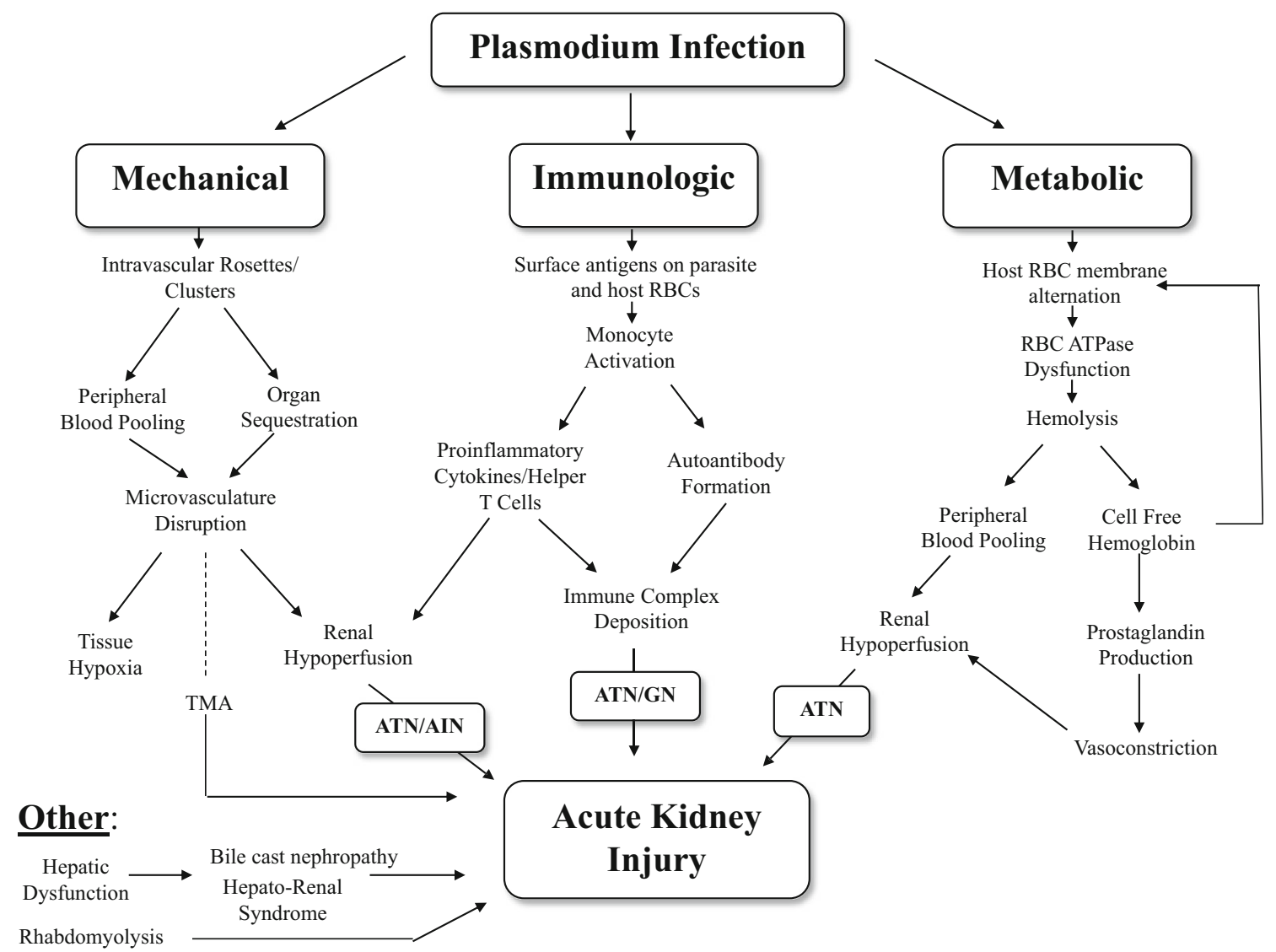

Fig. 1 Pathogenesis of malarial acute kidney injury (AKI)

flow to the kidneys and other vital organs causing tissue hypoxia [16-18]. The adhesive ligands on parasitized RBC membranes have been termed "knobs" and are composed of abnormal proteins encoded by the parasite's genome [19]. The protein that appears to be the most significant determinant of erythrocyte adhesiveness and malarial morbidity is called Plasmodium falciparum erythrocyte membrane protein (pfEMP) [19]. Other adhesive protein families have also been identified in the erythrocyte knobs: rifins, rosettins, and histidine-rich proteins [20-22]. In addition to RBC sequestration, the hypovolemia that develops from insensible fluid losses (i.e. fever, respiratory distress), poor oral intake, or vomiting contribute further to the hemodynamic derangements. Ultimately, this hemodynamic compromise results in acute tubular necrosis (ATN), the most common cause of malarial AKI. Direct tubular injury can result from hemoglobinuria due to RBC hemolysis [13]. "Blackwater fever" is a condition that describes hemolysis releasing hemoglobin directly into the blood vessels and into the urine resulting in kidney injury and potentially, failure [23]. This may be the result of $\mathrm{RBC}$ destruction from infection or a consequence of antimalarial drug-induced hemolysis; patients with G6PD deficiency are most at risk for developing this [13]. Less commonly, myoglobinuria from associated rhabdomyolysis can impair tubular function [13]. On histology, edema, cellular necrosis, and hemosiderin deposits can be visualized within the tubules of patients who develop ATN [24]. Hemoglobin casts within the tubular lumens, venules that contain infected red cells, and monocellular infiltration of the interstitium have also been documented [13].

Cytoadherence inciting microvascular disruption is also theorized to play a role in patients with malarial AKI and thrombotic microangiopathy (TMA) [25]. While there is no established direct causal relationship between the two, there are multiple case reports that document the occurrence of TMA in patients with malaria; $P$. vivax infection, in particular [25-28]. Alternatively, there have also been documented cases of renal impairment due to TMA caused by treatment with antimalarial agents such as mefloquine and quinine agents $[25,29]$. It has been suggested that quinine dependent antibodies reacting with platelets and other cells contribute to quinine induced TMA [29].

The second proposed mechanism for malarial AKI suggests that the renal damage is caused by immune dysregulation and subsequent inflammation [30, 31]. Surface antigens on both host red cells, as well as the parasite's own cells, activate peripheral blood mononuclear cells. This monocyte activation causes the release of proinflammatory cytokines such as TNF- $\alpha$ and interleukins (ILs) 1, 6, 8, and $\gamma$ [32]. The release of ILs, results in proliferation of helper $\mathrm{T}$ cells 
$\left(\mathrm{Th}_{1}\right.$ and $\left.\mathrm{Th}_{2}\right) . \mathrm{Th}_{1}$ proliferation induces an acute interstitial nephritis (AIN) and glomerulonephritis; $\mathrm{Th}_{2}$ activation drives activation of complement with subsequent immune complex deposition induced glomerulonephritis and interstitial nephritis $[14,33]$. Histologically, when the glomerulus is affected there is mesangial expansion and proliferation which causes the glomerulus to become swollen [34]. Additionally, its capillaries may contain parasitized RBCs and host monocytes $[13,34]$. Immunofluorescence can demonstrate immune complexes of malarial antigen and $\operatorname{IgG}, \operatorname{IgM}$, and C3 deposited in the mesangium and capillary wall $[13,14]$. Autoantibody formation such as anticardiolipin and antiphospholipid antibodies have also been implicated in the immune-mediated vascular pathology associated with malarial infections [13, 33, 35].

The third proposed mechanism by which malaria causes acute kidney injury is metabolic disruption [13]. Due to changes of the host red cell membrane by parasitic infection, as discussed earlier, there is a resultant change in erythrocyte magnesium-activated ATPase [36]. This in turn leads to a decrease in sodium concentration inside the cell triggering calcium influx into the cell, altering red cell deformability [13]. The end result is a change in red cell structure that not only shortens its lifespan but contributes to the peripheral pooling and organ sequestration that causes kidney injury $[13,36]$. Discussion of potential metabolic causes of AKI in malarial infection must also include renal damage from oxidative stress caused by cell-free hemoglobin (CFH) [37]. $\mathrm{CFH}$, from significant hemolysis of both healthy and infected RBCs, mediates red cell membrane phospholipid peroxidation. Changes in RBC membrane phospholipids not only changes its deformability (leading to aforementioned consequences- shortened lifespan and peripheral pooling) but it also initiates production of prostaglandin isomers $\left(\mathrm{F}_{2^{-}}\right.$ IsoP and IsoFs) [37]. These prostaglandins act as potent renal vasoconstrictors reducing renal blood flow and renal function.

Hepatic dysfunction has also been described as causing AKI in patients with malaria [14, 38, 39]. Evidence exists for bile cast nephropathy due to cholestatic hyperbilirubinemia from RBC hemolysis as another risk factor for malarial AKI [38]. Renal impairment may also be a consequence of hepato-renal syndrome [14].

\section{Presentation of malarial AKI}

Renal insufficiency in the setting of severe malarial infection commonly develops 3-7 days after the onset of fever; serum creatine typically improves in $17 \pm 6$ days [24, 40]. As high as $80 \%$ of patients with malaria can develop non-oliguric AKI [23]. In those with oliguric AKI, the oliguria can persist for weeks [24].

On laboratory evaluation, acidosis, hyponatremia, and hyperkalemia are the most common electrolyte abnormalities seen in these patients [24]. The acidosis is primarily lactic acidosis from tissue hypoxia [41]. Studies suggest that hyponatremia is secondary to the initial internal dilution and then sodium wasting before the onset of oliguria [13]. Hyperkalemia, on the other hand, is secondary to hemolysis, acidosis, and rarely, rhabdomyolysis. As mentioned, the anemia and thrombocytopenia are due primarily to malarial infection. However, if the patient develops TMA, there may be a continued worsening of their anemia and thrombocytopenia. Patients with malarial AKI may develop proteinuria due to glomerulonephritis [13]. Of note, while complement activation has been implicated in the pathogenesis of malarial AKI, complement levels are usually normal [14].

\section{Treatment of malarial AKI}

\section{Supportive treatment}

Initial treatment of malarial AKI is similar to AKI treatment in non-malarial infection, which primarily involves supportive care. One important difference is the use of intravenous (IV) fluid boluses. Previously, the World Health Organization (WHO) recommendations for significant malarial illness (i.e., those who presented with shock) included IV fluid bolus resuscitation with albumin or normal saline [24]. However, data from the Fluid Expansion as Supportive Therapy (FEAST) trial of fluid resuscitation in children with severe infection showed an increase in $48 \mathrm{~h}$ mortality in patients who were given fluid boluses vs those who were not [42]. On further subgroup analysis of children with vs without malaria, there was no evidence to suggest a difference in mortality between the groups signifying that fluid boluses were of no benefit to either group [42]. As such, fluid boluses should be avoided in the treatment of malarial AKI unless the patient has significant hypotension. Continuous IV fluids can be used judiciously with close patient monitoring for signs of fluid overload.

In the setting of oliguria, loop diuretics have shown no reduction in mortality, increase in recovery of function, or modification of need for renal replacement therapy [13, 43].

\section{Specific therapies}

If the patient demonstrates signs of fluid overload (i.e., pulmonary edema, congestive heart failure), develops refractory electrolyte abnormalities (i.e., hyperkalemia or metabolic acidosis), or symptomatic uremia, they may require specific therapies such as dialysis. Malarial infection also places these patients in a hypercatabolic state, increasing their risk for needing dialysis [24]. As malaria-associated AKI may be rapidly progressive, it is recommended that renal replacement therapy be started as early as possible once indicated [23]. Studies of adult patients have demonstrated that, if available, 
intermittent hemodialysis and continuous veno-venous hemodiafiltration (CVVHDF) are preferred modalities compared to peritoneal dialysis (PD) $[23,24,43]$. If CVVHDF is used, a dose of $35 \mathrm{ml} / \mathrm{kg}$ is postulated to lower the risk of death when compared to $20 \mathrm{ml} / \mathrm{kg}$ [43, 44]. In children, there is evidence that PD is effective in treating renal insufficiency due to severe malaria. This is important to note as PD may be the only modality available in some endemic, or resourcelimited areas [13, 24]. Interestingly, a randomized control study in Bangladesh patients demonstrated that IV prostacyclin reduced the development of AKI [13, 23]. Another randomized control trial found that acetaminophen greatly reduced serum creatine and lowered risk of AKI in patients with moderate to severe malaria [45]. As acetaminophen can be hepatotoxic, it must be used with caution as patients with malaria can experience liver dysfunction [46].

It is important to maintain a high index of suspicion for TMA, particularly when hemolytic anemia and thrombocytopenia persist post adequate malaria treatment, especially if medications such as quinine were given for treatment [25]. Page et al. [29] compared patients with quinine-induced TMA to patients diagnosed with TTP-94\% (19 patients) required dialysis, many concurrently requiring plasma exchange; $78 \%$ of these patient went on to develop CKD [29, 40].

Managing malarial AKI can also include use of urinary biomarkers of kidney injury. Neutrophil gelatinaseassociated lipocalin (NGAL) and kidney injury molecule-1 (KIM-1) have been studied in patients with $P$. falciparum malaria with one study identifying $31 \%$ with malarial AKI using urinary markers whose creatinine values were normal on presentation [14]. Given potential significant sequelae of malarial infection, current treatment efforts continue to focus on prevention. Research in vaccine development has led to the discovery that numerous time points in the life cycle of the Plasmodium are susceptible to antibodies [47]. This is the driving premise behind current protein vaccines, many of which are now in phase I/II clinical testing [47, 48].

\section{Outcomes of malarial AKI}

Across multiple cohorts and studies, severe malaria was consistently among the top etiologies of AKI in pediatric patients admitted to hospitals in developing countries [2, 9, 49-51]. Mortality rates, in hospital deaths in particular, vary from $20 \%-51 \%[5,6,9$, $50,52]$. Not surprisingly, the dearth of access to renal replacement modalities plays a crucial role in the outcomes of these patients. Other poor prognostic factors include delayed referral, high parasite load, multi-system involvement, younger age, severe jaundice, hypotension, severe anemia, and oliguria [13, 53]. Assounga et al. (2000) found that up to $12 \%$ of patients developed chronic impairment in kidney function after malarial AKI [51]. However, more systematic, dedicated, and long-term assessments are needed to fully understand the impact of AKI caused by malaria.

In summary, malaria continues to be a global threat, with the pediatric population being especially vulnerable. AKI is a common occurrence in pediatric patients with severe malarial infection. The pathogenesis of malarial AKI is thought to include hemodynamic derangements, immune-mediated glomerular injury, and metabolic disturbances. Patients with severe malaria should be monitored closely for evidence of renal involvement, including refractory electrolyte abnormalities, and fluid overload. It is also important to maintain a high index of suspicion for TMA. If patients develop oliguric AKI, treatment should start with supportive therapies, avoiding fluid boluses unless the patient has severe hypotension. Renal replacement therapy should be considered early on and initiated when supportive therapy is insufficient. There is no consensus on preferred dialysis modality so available resources should dictate the modality used. In order to modify risk of mortality, early identification and treatment of malarial AKI is of paramount importance in patients who develop severe malarial infection.

Questions (Answers are provided after the reference list)

1. Renal compromise is most often seen with what plasmodium species?
A. Plasmodium malariae
B. Plasmodium vivax
C. Plasmodium ovale
D. Plasmodium falciparum

2. What is the most common cause of acute kidney injury (AKI) in patients with malaria?
A. Acute tubular necrosis
B. Acute glomerulonephritis
C. Renal cystic disease
D. Urinary obstruction

3. What are the most frequently encountered electrolyte abnormalities seen in patients with malarial AKI?
A. Hyponatremia and hyperkalemia
B. Hyponatremia and metabolic alkalosis
C. Hypokalemia and metabolic acidosis
D. Hypernatremia and hypokalemia

4. Which is true regarding IV bolus fluid resuscitation in patients with severe infection according to results from the FEAST trial?

A. A $20 \mathrm{~mL} / \mathrm{kg}$ bolus of normal saline improved $48-\mathrm{h}$ mortality in patients with severe infection 
B. A $20 \mathrm{~mL} / \mathrm{kg}$ bolus of albumin improved 48 -h mortality in patients with severe infection

C. A $20 \mathrm{~mL} / \mathrm{kg}$ IV bolus of albumin increased mortality in patients with severe infection but normal saline did not

D. Both normal saline and albumin IV fluid boluses increased 48-h mortality in patients with severe infection

5. What disease has been associated with malarial infection itself or certain drugs used for treatment of malaria?
A. ANCA vasculitis
B. FSGS
C. Thrombotic microangiopathy
D. Lupus nephritis

Acknowledgements Geraldo Bezerra da Silva, Junior, MD, PHD. T-32 Training Grant (\#5T32DK007110-44).

\section{Compliance with ethical standards}

Conflict of interest The authors declare no conflict of interest.

Publisher's note Springer Nature remains neutral with regard to jurisdictional claims in published maps and institutional affiliations.

\section{References}

1. Mace KE, Arguin PM (2017) Malaria surveillance - United States, 2014. MMWR Surveill Summ 66:1-24

2. Conroy AL, Hawkes M, Elphinstone RE, Morgan C, Hermann L, Barker KR, Namasopo S, Opoka RO, John CC, Liles WC, Kain KC (2016) Acute kidney injury is common in pediatric severe malaria and is associated with increased mortality. Open Forum Infect Dis 3:ofw046

3. Jallow M, Casals-Pascual C, Ackerman H, Walther B, Walther M, Pinder M, Sisay-Joof F, Usen S, Jallow M, Abubakar I, Olaosebikan R, Jobarteh A, Conway DJ, Bojang K, Kwiatkowski D (2012) Clinical features of severe malaria associated with death: a 13-year observational study in the Gambia. PLoS One 7:e45645

4. Waller D, Krishna S, Crawley J, Miller K, Nosten F, Chapman D, ter Kuile FO, Craddock C, Berry C, Holloway PA, Brewster D, Greenwood BM, White NJ (1995) Clinical features and outcome of severe malaria in Gambian children. Clin Infect Dis 21:577-587

5. von Seidlein L, Olaosebikan R, Hendriksen IC, Lee SJ, Adedoyin OT, Agbenyega T, Nguah SB, Bojang K, Deen JL, Evans J, Fanello CI, Gomes E, Pedro AJ, Kahabuka C, Karema C, Kivaya E, Maitland K, Mokuolu OA, Mtove G, Mwanga-Amumpaire J, Nadjm B, Nansumba M, Ngum WP, Onyamboko MA, Reyburn H, Sakulthaew T, Silamut K, Tshefu AK, Umulisa N, Gesase S, Day NP, White NJ, Dondorp AM (2012) Predicting the clinical outcome of severe falciparum malaria in African children: findings from a large randomized trial. Clin Infect Dis 54:1080-1090

6. Esezobor CI, Ladapo TA, Osinaike B, Lesi FE (2012) Paediatric acute kidney injury in a tertiary hospital in Nigeria: prevalence, causes and mortality rate. PLoS One 7:e51229

7. Wuhl E, Trivelli A, Picca S, Litwin M, Peco-Antic A, Zurowska A, Testa S, Jankauskiene A, Emre S, Caldas-Afonso A, Anarat A,
Niaudet P, Mir S, Bakkaloglu A, Enke B, Montini G, Wingen AM, Sallay P, Jeck N, Berg U, Caliskan S, Wygoda S, HohbachHohenfellner K, Dusek J, Urasinski T, Arbeiter K, Neuhaus T, Gellermann J, Drozdz D, Fischbach M, Moller K, Wigger M, Peruzzi L, Mehls O, Schaefer F (2009) Strict blood-pressure control and progression of renal failure in children. N Engl J Med 361: $1639-1650$

8. Imani PD, Odiit A, Hingorani SR, Weiss NS, Eddy AA (2013) Acute kidney injury and its association with in-hospital mortality among children with acute infections. Pedia Nephrol 28:2199-2206

9. Olowu WA, Adelusola KA (2004) Pediatric acute renal failure in southwestern Nigeria. Kidney Int 66:1541-1548

10. Kapoor K, Gupta S (2012) Malarial acute kidney injury in a paediatric intensive care unit. Trop Doc 42:203-205

11. Dondorp AM, Lee SJ, Faiz MA, Mishra S, Price R, Tjitra E, Than M, Htut Y, Mohanty S, Yunus EB, Rahman R, Nosten F, Anstey NM, Day NP, White NJ (2008) The relationship between age and the manifestations of and mortality associated with severe malaria. Clin Infect Dis 47:151-157

12. Eiam-Ong S, Sitprija V (1998) Falciparum malaria and the kidney: a model of inflammation. Am J Kidney Dis 32:361-375

13. Barsoum RS (2000) Malarial acute renal failure. J Am Soc Nephrol $11: 2147-2154$

14. Silva GBDJ, Pinto JR, Barros EJG, Farias GMN, Daher EF (2017) Kidney involvement in malaria: an update. Rev Inst Trop Sao Paulo 59:e53

15. Berendt AR (1993) Sequestration and its discontents: infected erythrocyte-endothelial cell interactions in Plasmodium falciparum malaria. Res Immunol 144:740-745 discussion 754-762

16. Sitprija V (1988) Nephropathy in falciparum malaria. Kidney Int 34:867-877

17. Kyes S, Horrocks P, Newbold C (2001) Antigenic variation at the infected red cell surface in malaria. Annu Rev Microbiol 55:673-707

18. Pongponratn E, Riganti M, Punpoowong B, Aikawa M (1991) Microvascular sequestration of parasitized erythrocytes in human falciparum malaria: a pathological study. Am J Trop Med Hyg 44: $168-175$

19. Baruch DI, Pasloske BL, Singh HB, Bi X, Ma XC, Feldman M, Taraschi TF, Howard RJ (1995) Cloning the P. falciparum gene encoding PfEMP1, a malarial variant antigen and adherence receptor on the surface of parasitized human erythrocytes. Cell 82:77-87

20. Kyes SA, Rowe JA, Kriek N, Newbold CI (1999) Rifins: a second family of clonally variant proteins expressed on the surface of red cells infected with Plasmodium falciparum. Pro Natl Acad Sci U S A 96:9333-9338

21. Helmby H, Calerier L, Pettersson U, Wahlgren M (1993) Helmby H, Cavelier L, Pettersson U, Wahlgren M. Rosetting Plasmodium falciparum-infected erythrocytes express unique strain-specific antigens on their surface. Infect Immun 61(1):284-288

22. Parra ME, Evans CB, Taylor DW (1991) Identification of Plasmodium falciparum histidine-rich protein 2 in the plasma of humans with malaria. J Clin Microbiol 29:1629-1634

23. Plewes K, Turner GDH, Dondorp AM (2018) Pathophysiology, clinical presentation, and treatment of coma and acute kidney injury complicating falciparum malaria. Curr Opin Infect Dis 31:69-77

24. Kamath N, Iyengar A (2017) Infections and the kidney: a tale from the tropics. Pedia Nephro

25. Bhadauria D, Vardhan H, Kaul A, Sharma RK, Gupta A, Prasad N, Jain M (2017) P. vivax malaria presenting as thrombotic microangiopathy. J Assoc Physicians India 65:28-31

26. Sinha A, Singh G, Bhat AS, Mohapatra S, Gulati A, Hari P, Samantaray JC, Dinda AK, Agarwal SK, Bagga A (2013) Thrombotic microangiopathy and acute kidney injury following vivax malaria. Clin Exp Nephrol 17:66-72 
27. Saharan S, Kohli U, Lodha R, Sharma A, Bagga A (2009) Thrombotic microangiopathy associated with Plasmodium vivax malaria. Pedia Nephrol 24:623-624

28. Sharma J, Bharadawa K, Shah K, Dave S (1993) Plasmodium vivax malaria presenting as hemolytic-uremic syndrome. Indian Pedia 30:369-371

29. Page EE, Little DJ, Vesely SK, George JN (2017) Quinine-induced thrombotic microangiopathy: a report of 19 patients. Am J Kidney Dis 70:686-695

30. Spitz S (1946) The pathology of acute falciparum malaria. Mil Surg 99:555-572

31. Sitprija V, Indraprasit S, Pochanugool C, Benyajati C, Piyaratn P (1967) Renal failure in malaria. Lancet 1:185-188

32. Sitprija V, Napathorn S, Laorpatanaskul S, Suithichaiyakul T, Moollaor P, Suwangool P, Sridama V, Thamaree S, Tankeyoon M (1996) Renal and systemic hemodynamics, in falciparum malaria. Am J Nephrol 16:513-519

33. Urquhart AD (1994) Putative pathophysiological interactions of cytokines and phagocytic cells in severe human falciparum malaria. Clin Infect Dis 19:117-131

34. Mishra SK, Das BS (2008) Malaria and acute kidney injury. Semin Nephrol 28:395-408

35. Jakobsen PH, Morris-Jones SD, Hviid L, Theander TG, HoierMadsen M, Bayoumi RA, Greenwood BM (1993) Antiphospholipid antibodies in patients with Plasmodium falciparum malaria. Immunology 79:653-657

36. Mikkelsen RB, Tanabe K, Wallach DF (1982) Membrane potential of Plasmodium-infected erythrocytes. J Cell Biol 93:685-689

37. Plewes K, Kingston HWF, Ghose A, Maude RJ, Herdman MT, Leopold SJ, Ishioka H, Hasan MMU, Haider MS, Alam S, Piera KA, Charunwatthana P, Silamut K, Yeo TW, Faiz MA, Lee SJ, Mukaka M, Turner GDH, Anstey NM, Jackson Roberts L 2nd, White NJ, Day NPJ, Hossain MA, Dondorp AM (2017) Cell-free hemoglobin mediated oxidative stress is associated with acute kidney injury and renal replacement therapy in severe falciparum malaria: an observational study. BMC Infect Dis 17:313

38. Mohapatra MK, Behera AK, Karua PC, Bariha PK, Rath A, Aggrawal KC, Nahak SR, Gudaganatti SS (2016) Urinary bile casts in bile cast nephropathy secondary to severe falciparum malaria. Clin Kidney J 9:644-648

39. Al-Mendalawi MD (2013) Acute renal failure associated with malaria in children. Saudi J Kidney Dis Transpl 24:1255

40. Koopmans LC, van Wolfswinkel ME, Hesselink DA, Hoorn EJ, Koelewijn R, van Hellemond JJ, van Genderen PJ (2015) Acute kidney injury in imported Plasmodium falciparum malaria. Malar J 14:523

41. World Health Organization (2014) Severe malaria. Tropical Med Int Health 19(Suppl 1):7-131
42. Maitland K, Kiguli S, Opoka RO, Engoru C, Olupot-Olupot P, Akech SO, Nyeko R, Mtove G, Reyburn H, Lang T, Brent B, Evans JA, Tibenderana JK, Crawley J, Russell EC, Levin M, Babiker AG, Gibb DM, Group FT (2011) Mortality after fluid bolus in African children with severe infection. N Engl J Med 364:24832495

43. Das BS (2008) Renal failure in malaria. J Vector Borne Dis 45:8397

44. Pannu N, Klarenbach S, Wiebe N, Manns B, Tonelli M (2008) Renal replacement therapy in patients with acute renal failure: a systematic review. JAMA 299:793-805

45. Plewes K, Kingston HWF, Ghose A, Wattanakul T, Hassan MMU, Haider MS, Dutta PK, Islam MA, Alam S, Jahangir SM, Zahed ASM, Sattar MA, Chowdhury MAH, Herdman MT, Leopold SJ, Ishioka H, Piera KA, Charunwatthana P, Silamut K, Yeo TW, Lee SJ, Mukaka M, Maude RJ, Turner GDH, Faiz MA, Tarning J, Oates JA, Anstey NM, White NJ, Day NPJ, Hossain MA, Roberts Ii LJ, Dondorp AM (2018) Acetaminophen as a renoprotective adjunctive treatment in patients with severe and moderately severe falciparum malaria: a randomized, controlled, open-label trial. Clin Infect Dis 67:991-999

46. Bhattacharjee P, Dubey S, Gupta VK, Agarwal P, Mahato MP (2013) The clinicopathologic manifestations of Plasmodium vivax malaria in children: a growing menace. J Clin Diagn Res 7:861-867

47. Draper SJ, Angov E, Horii T, Miller LH, Srinivasan P, Theisen M, Biswas S (2015) Recent advances in recombinant protein-based malaria vaccines. Vaccine 33:7433-7443

48. Hoffman SL, Vekemans J, Richie TL, Duffy PE (2015) The march toward malaria vaccines. Am J Prev Med 49:S319-S333

49. Esezobor CI, Ladapo TA, Lesi FE (2015) Clinical profile and hospital outcome of children with severe acute kidney injury in a developing country. J Trop Pedia 61:54-60

50. Anochie IC, Eke FU (2005) Acute renal failure in Nigerian children: Port Harcourt experience. Pedia Nephrol 20:1610 1614

51. Assounga AG, Assambo-Kieli C, Mafoua A, Moyen G, Nzingoula S (2000) Etiology and outcome of acute renal failure in children in Congo-Brazzaville. Saudi J Kidney Dis Transpl 11:40-43

52. Halle MP, Lapsap CT, Barla E, Fouda H, Djantio H, Moudze BK, Akazong CA, Priso EB (2017) Epidemiology and outcomes of children with renal failure in the pediatric ward of a tertiary hospital in Cameroon. BMC Pedia 17:202

53. Sheiban AK (1999) Prognosis of malaria associated severe acute renal failure in children. Ren Fail 21:63-66

Answers 1. D; 2. A; 3. A; 4. D; 5. C 